\title{
AD-A276 656
}

1992

Executive Research Project

F40

\section{Application of Artificial Intelligence to the DoD Corporate Information Management (CIM) Program}

Howard E. Bylund, Jr.

This dominent has beed appsoved

for public telease and salp; to

Antribution is unlimired.

Faculty Research Advisor Mr. Coleman O. Bevis

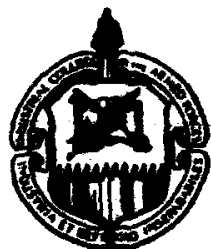

The Industrial College of the Armed Forces

National Defense University

Fort McNair, Washington, D.C. 20319-6000

$94^{-3} 39$ DTIC QUALTTY INSPECTED B 


$$
\begin{gathered}
\text { Best } \\
\text { Available } \\
\text { Copy }
\end{gathered}
$$


Unclassified

\section{REPORT DOCUMENTATION PAGE}

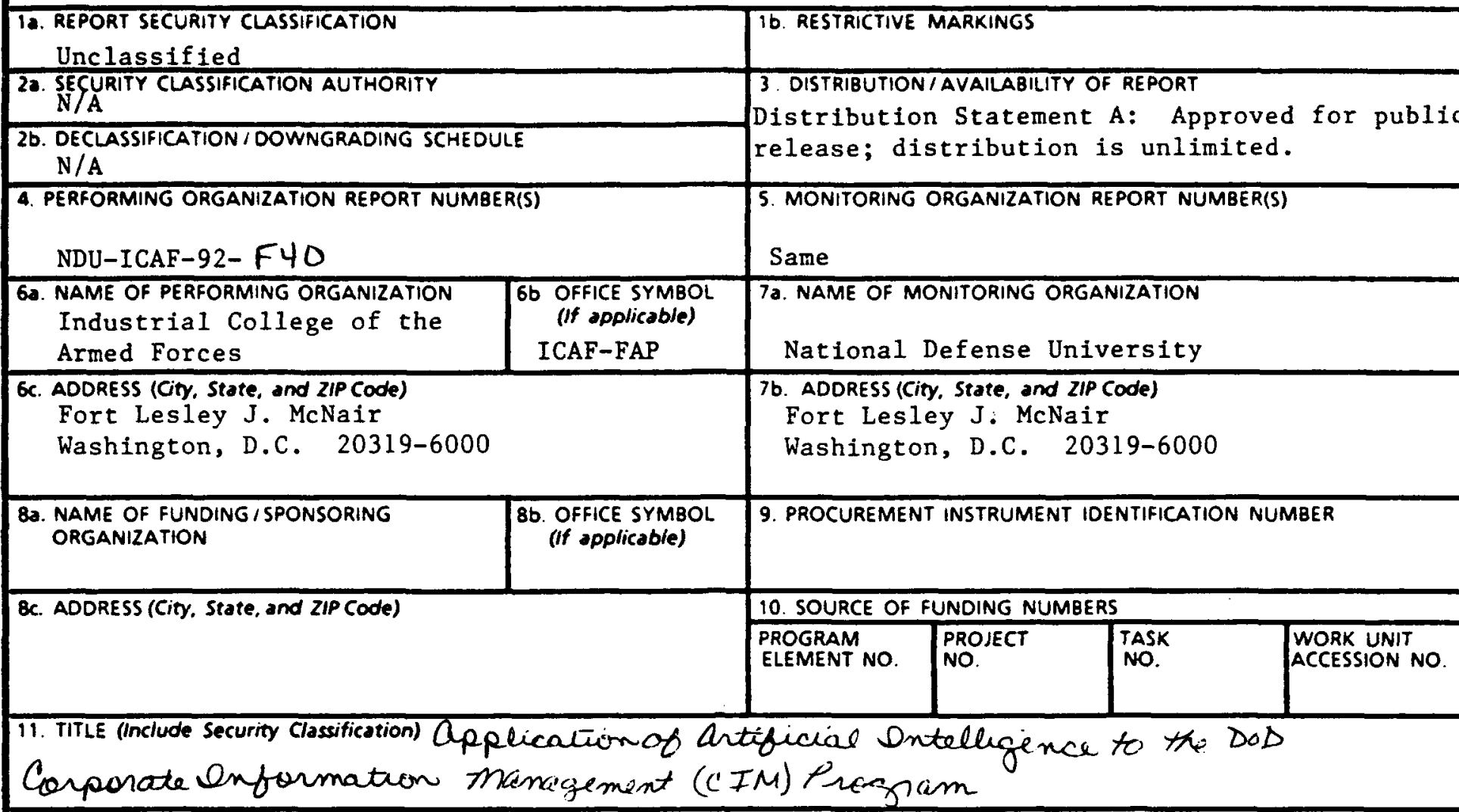

12. Personal aUthor(s) Houarde \&. Bylund, g

\begin{tabular}{|c|c|c|c|}
\hline $\begin{array}{c}\text { 13a. TYPE OF REPORT } \\
\text { Research }\end{array}$ & $\begin{array}{c}\text { 13b. TIME COVERED } \\
\text { FROM Aug } 91\end{array}$ TO Apr 92 & $\begin{array}{c}\text { 14. DATE OF REPORT (Year, Month, Day) } \\
\text { April } 92\end{array}$ & PAGE COUNT 3 2 \\
\hline
\end{tabular}

16. SUPPLEMENTARY NOTATION

\begin{tabular}{|c|c|c|c|}
\hline \multicolumn{3}{|c|}{ COSATI CODES } & \multirow[t]{3}{*}{ 18. SUBJECT TERMS (Continue on reverse if necessary and identify by block number) } \\
\hline FIELD & GROUP & SUB-GROUP & \\
\hline & & & \\
\hline & & & \\
\hline
\end{tabular}

19. ABSTRACT (Continue on reverse if necessary and identify by block number)

\section{SEE ATTACHED}

20. DISTRIBUTION /AVAILABILITY OF ABSTRACT GUNCLASSIFIEDNNLIMITED $\square$ SAME AS RPT.

22a. NAME OF RESPONSIBLE INDIVIDUAL Judy Clark

DD FORM 1473,84 MAR
83 APR édition may be used until exhausted. All other editions are obsolete.
21. ABSTRACT SECURITY CLASSIFICATION

DTIC USERS

22b. TELEPHONE (Include Areo Code) 22C. OFFICE SYMBOL (202) 475-1889 ICAF-FAP.

SECURITY CLASSIFICATION OF THIS PAGE

Unclassified 


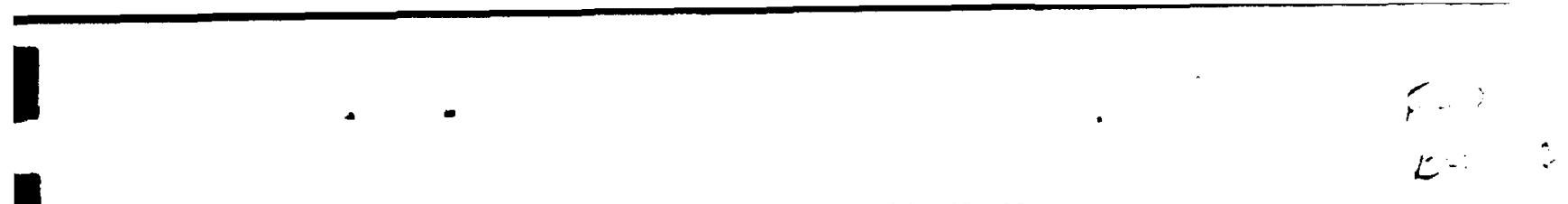

ABSTRACT

This paper analyzes the DOD Corporate Information Management (CIM) Program and the level of Artificial Intelligence being inserted into the program. This analysis is done by using commercial business activities as a baseline. It addresses the introduction of Artificial Intelligence (AI) through the benchmark process of the DOD CIM. It was found that this benchmark process of the CIM, similar to the DOD Total Quality Management (TQM) process, is determiring the level of technology insertion into the CIM. It is recommended that this process continue and that, as with other technologies, AI be incorporated as demonstrated beneficial through the benchmark process. 
1992

Executive Research Project

F40

\section{Application of Artificial Intelligence to the DoD Corporate Information Management (CIM) Program}

Howard E. Bylund, Jr.

Faculty Research Advisor Mr. Coleman O. Bevis

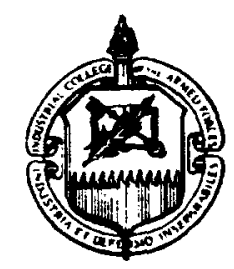

\begin{tabular}{|ll|}
\hline Accesion for \\
\hline NTIS CRA\&l & 0 \\
DTIC TAB & $\square$ \\
Unannounced & $\square$ \\
Justification & \\
\hline
\end{tabular}

By

Distribution /

Availability Corjes

\begin{tabular}{|l|l|}
\hline Dist & $\begin{array}{c}\text { Avail and ior } \\
\text { Special }\end{array}$ \\
\hline$A-1$ & \\
\hline
\end{tabular}

The Industrial College of the Armed Forces National Defense University

Fort McNair, Washington, D.C. 20319-6000 


\section{DISCLAIMER}

This research report represents the views of the author and does not necessarily reflect the official opinion of the Industrial College of the Armed Forces, the National Defense University, or the Department of Defense.

This document is the property of the United States Government and is not to be reproduced in whole or in part for distribution outside the federal executive branch without permission of the Director of Research and Publications, Industrial College of the Armed Forces, Fort Lesley J. McNair, Washington, D.C. 20319-6000. 
TABLE OF CONTENTS

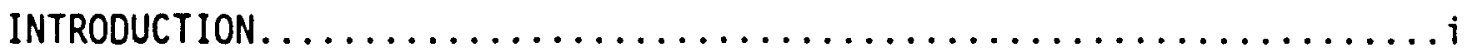

1. PRODUCTIVITY, INDUSTRY AND INFORMATION TECHNOLOGY...............

2. INFORMATION AS AN ASSET OF A CORPORATION......................

2.1. VALUE TO THE EXECUTIVE..............................

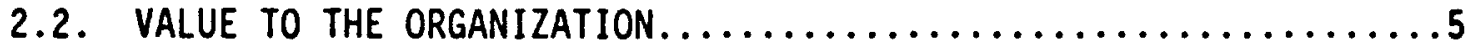

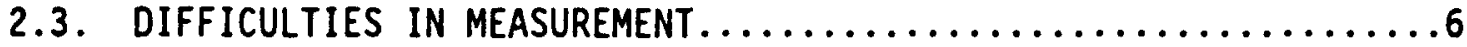

2.4. STRATEGIC IMPROVEMENTS $\ldots \ldots \ldots \ldots \ldots \ldots \ldots \ldots \ldots \ldots \ldots \ldots$

2.4.1. Indirect benefits $\ldots \ldots \ldots \ldots \ldots \ldots \ldots \ldots \ldots \ldots \ldots \ldots, \ldots$

2.4.2. Inferred benefits.................................

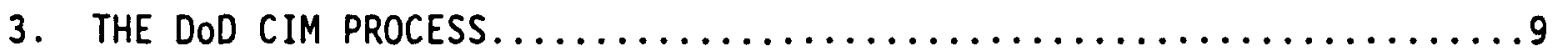

3.1. ESTIMATE OF THE SITUATION IN THE GOVERNMENT $\ldots \ldots \ldots \ldots \ldots \ldots \ldots, \ldots$

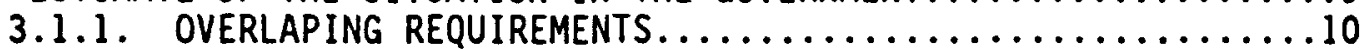

3.1.2. NON-OVERLAPPING IMPLEMENTATIONS..................

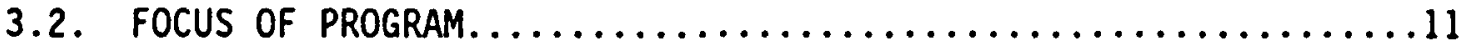

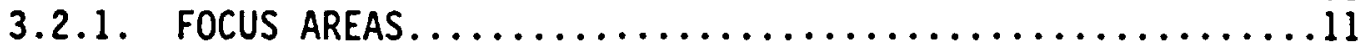

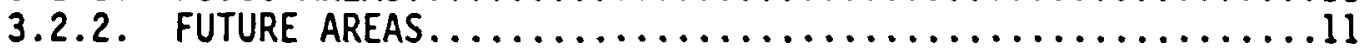

3.3. THE DEVELOPMENT PROCESS .....................................

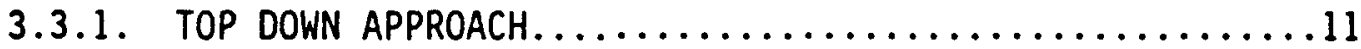

3.3.2. STRATEGIES FOR IMPLEMENTATION....................

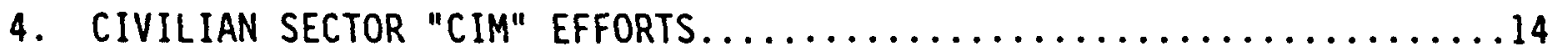

4.1. "BUSINESS PROCESS REDESIGN" .............................

4.2. EFFECTIVENESS OF THE PROCESS .........................

4.3. KNOWLEDGE MANAGEMENT AND THE BASELINE PROCESS $\ldots \ldots \ldots \ldots \ldots \ldots 17$

5. ARTIFICIAL INTELLIGENCE AS A BASELINE $\ldots \ldots \ldots \ldots \ldots \ldots \ldots \ldots \ldots$

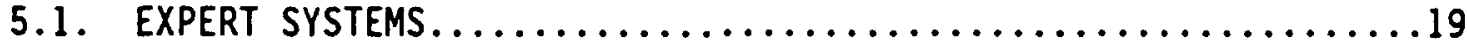

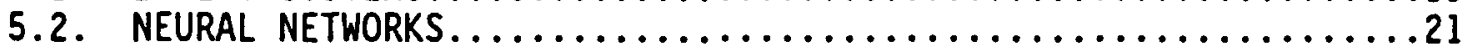

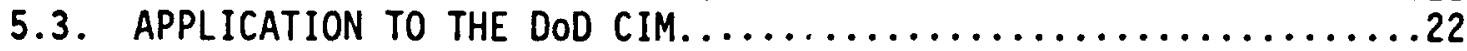

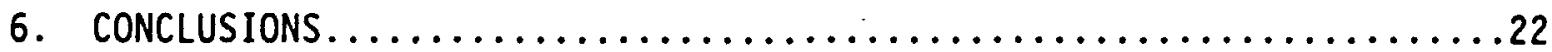

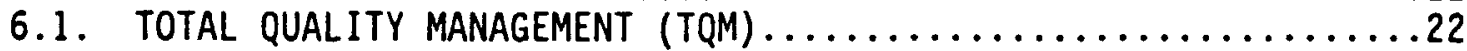

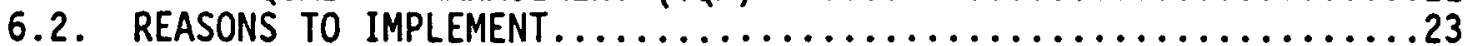

6.3. ORGANIZATIONAL MOMENTUM...............................23

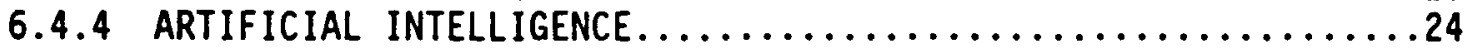




\section{INTRODUCTION}

The Department of Defense is faced with a reduction in budget in excess of $30 \%$-- and we may see a reduction in excess of this amount. As the budget is reduced our capability to respond to many situations will decline. How significant the decline of capability will be will depend on how skilled we are with increasing our efficiency. This increase in productivity may be through the application of increased technology, improved business processes or a combination of both.

In WW II an artillery unit had a limited amount of firepower. As was demonstrated by the Russians in Orsha, a significant increase in capability could be attained by the introduction of a technical alternative, a mass rocket launching system. The introduction of this capability was resisted by our Army. Yet each war more clearly defined the need for the system. Not until the reduction of the available amount of manpower was projected did we accept the MLRS into the Army. An increase in capability and a simultaneous reduction in required manpower. Necessity was the mother of invention. 
DESERT STORM showed the application of technology on the battle front. The technology gave us the effective strength of a force twice the size. The possibilities for the future are before us; we can do less with less as the budget declines or we can challenge ourselves with doing the same or more with the existing budget. The DMR has already identified $\$ 35$ million dollars to be saved through "improvements in the delivery of mission capabilities and efficiencies." 1 The challenge is here and now. 
"Know your enemy and know yourself;

in a hundred battles, you will never be defeated.

When you are ignorant of the enemy but know yourself, your chances of winning or losing are equal.

If ignorant of both your enemy and of yourself, you are sure to be defeated in every battle." ..- Sun Tizu, 400 B.C.

\section{PRODUCTIVITY, INDUSTRY AND INFORMATION TECHNOLOGY}

The success of any firm (to include the Department of Defense) is related to many factors. These include the productivity efficiency of the firm to produce products/services as well as the quality of the firm's products, service after the sale, response time from concept to product, and even the firm's ability to predict the market. For many years CEOs across industry have approached the question of "information systems" and "information technology" with trepidation. They reasoned that the more information that was available the easier it would be to focus the companies' efforts, determine areas to improve and thus improve the productivity of their company. Sun Tzu would be proud to see his philosophy of information being applied to the modern business environment.

There have been a few notable instances where a change has cut across the entire industrial market ${ }^{2}$. Do investments in "information systems" or "information technology" fall in this category? Do the profits of a company relate to the expenditures made for "information systems."

2 The industrial revolution is a primary example where technology increased the productivity of the nation. 
Informatior Technology has made great strides in the past few years. From the point of technology it is the intersection of three technologies: communications, computers and software. For many reasons these three areas are coming together ${ }^{3}$.

It is helpful to look at the use of this "information technology." For the Department of Defense, the computer serves only one purpose: the provisioning of services and capabilities. We do not sell "information technology" and cannot determine their value from the market. Thus we can only determine their value from the cost savings they add to value of the services they provide. In FY-92 the budget for "information technology" was $\$ 9.2$ billion. This means that we believe that this is the most cost effective method of providing the services.

For years we have spent dollars automating areas where the savings were obvious such as in payroll or accounting. However, the gains are not as obvious in the implementation of information systems. Toffler cautions that "wherever we see new radical technology and an old work system, it is likely that the technology is misapplied and its real advantage wasted. History has shown repeatedly that truly advanced technologies require truly advanced work methods and organizations." 4

${ }^{3}$ The 1982 Modified Consent Decree between AT\&T and the Department of Justice is often remembered for breaking up the communications monopoly. It was also significant in that it allowed AT\&T to enter the computer business.

${ }^{4}$ Toffler, "Power Shift", p. 209 


\section{INFORMATION AS AN ASSET OF A CORPORATION}

\subsection{VALUE TO THE EXECUTIVE}

The executive in an organization is responsible for providing direction to the organization. Decisions are, to a large extent, formed in this environment by information which is "soft." This soft information is the information which is subtle in nature, difficult to quantify and not placed easily into a data matrix. However, Executive Support Systems are making inroads in dealing with this type of information.

Rockart and LeLong point to six ways in which information technology enhances the managers understanding of the business ${ }^{5}$ :

- Improved access to e ternal data.

- Ability to combine data from multiple sources.

- Data presented in more meaningful formats.

- Improved analytic and modeling capabilities.

- Ability to surface and test assumptions about the business.

- Off-hours data access.

However there is not total agreement in the ranks of management on the impact of this on their decision abilities. From the case studies which are available in the literature there seems to be two categories of companies and associated value to these systems.

The first type of company is the one which utilizes the system to restructure or reform the company processes in an effort to gain a competitive edge. This type of company is typically an "overachiever" and is continually looking for a competitive edge. The Vice Chairman of Xerox (recent winner of the Malcomb Baldrich Quality award) stated, "The system

5John F. Rockart and David W. DeLong, "Executive Support Systems", 1988, Dow Jones-Irwin, p. 148 
is embedded in the business process of our senior management and is an integral part of our business planning process and our operations reviews. Frankly, the Executive Support System is so ingrained in the way we manage the business that it's difficult to imagine life without it ${ }^{6}$.

Other companies tend to automate their standard business process and thus there is little increase in the value to the organization. Rockert and Delong make the point that there are many ESSs which fall in to disuse when the the CEO of the organization changes. This is proof positive that the ESS was not incorporated into the system and was not improving productivity.

This is perhaps the litmus test. Each executive has a personal goal of improving his productivity. As the executive operates he compares the impact of the ESS to his daily operation. If he finds it increases his productivity he will continue to use the system even absent any directive to use it. James Martini asserts that "the return on investment of most personal computers use is quite low....about 10 to 20 percent.... because they are used for automating individual tasks. When there is higher-level planning and personal computers are used for automating business processes, a three-fold return on investment may be obtained. However, when a strategic vision is implemented by means of personal computers, a

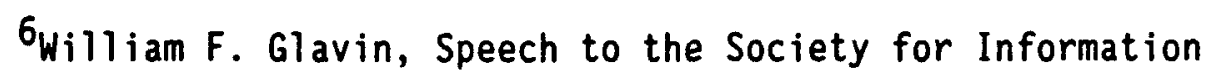
Management, Miami, Florida, March 27, 1987 
ten-fold return on investment is sometimes obtained." 7

\subsection{VALUE TO THE ORGANIZATION}

Over the past years Defense organizations have been faced with the problem of balancing the investments of the corporation between several possible assets; buildings, machine tools, training, R\&D and "information technology." The organization has had to determine a course of action which would provide the optimal use of the resources. The executive has had to determine the value of the investment in this area.

This has not been an easy task. The difficulties in judging the value to the organization are more difficult than judging the value of ESSs. The executive is required to judge the value of the system for the organization and from his viewpoint the decision is difficult. The amount of information available for the decision usually less than required to make an informed decision.

There have been numerous studies which have attempted to evaluate the "value of information systems." In 1988 and again in 1989 Computerworld attempted to evaluate how effectively companies utilized information systems through the utilization of weighted criteria. The weights and associated criteria included:

$30 \% \quad$ Information System Budget as \% of Revenue

15\% Market value of installed equipment

15\% Profitability during past five years

$10 \%$ Below average spending on staff

$15 \% \quad \%$ of total budget spent on training

$15 \% \quad \%$ of employees with PCs/terminals

7James Martin, "Information Engineering." p. 142 
In summary, $60 \%$ of the survey related to how much money has been spent on information systems. Only $15 \%$ relates to the success of the company. As long as you are successful and spent significant money on computers, you would do well in the rating. This type of analysis does not determine which company was more effective in their application of the equipment at hand.

\subsection{DIFFICULTIES IN MEASUREMENT}

In September 1989, "Information Week" introduced the concept of profits per employee. Conceptually this comes a bit closer to the to the analysis of the problem. If one views the information system as a "tool" for the employee, and the manager is more effective as a result, the company should become more profitable. It should be examined in the same way other capital expenditures are examined. The problem is to determine which profits are the result of the investment in Information Systems and which are the normal result of the management. This prevents the examination of direct cost to benefit ratios. Additional difficulties are associated with the use of profits/employee ratio. Firms vary as to their basic structure. Some have large capital base with few employees and others are the reverse. Some consume large quantities of resources with few employees and others do not. To judge one "better" in the use of information systems would be difficult from industry to industry. However, this approach could be useful within a narrow business sector. This approach may be improved on by focusing in on the profits to management employee ratio as management spends 18 times as much as operations. 8

8"The Business Value of Computers", Mr. Paul Strassmann, 1990 
By elimination of extraneous data the amount of actual return on management can be determined. This analysis is quite involved and requires the collection of significant amounts of raw data. This was done in the Management Productivity and Information Technology (MPIT) project $^{9}$. For the MPIT project significant amounts of data were collected from hundreds of firms. The data was specifically designed to determine the impact of information technology on management. This "return-on-management" 10 analysis reveals the relation between mananament productivity several important factors, including the amount spent on information systems. Several observations can be made from the data:

a. As management productivity increases less money is spent on information technology.

b. As management productivity increases the deployment of information technology increases for operation and decreases for management. c. Where management productivity is high, administrative functions receive higher proportion of the information technology, this is concurrent with reductions in the administrative overhead ratios.

Thus increases in a corporations efficiency are primarily related to the application of information systems in; personnel reducing initiatives in the administrative area, and applications in the operations/production area which increase production efficiency.

Direct improvements in Management productivity are not supported by Strassman's thorough research. Applications in the management area are more elusive.

${ }^{9}$ Funded by the Strategic Planning Institute.

10"The Business Value of Computers", Mr. Paul Strassmann, 1990 


\subsection{STRATEGIC IMPROVEMENTS}

Outside of the direct area of increased productivity there are areas which affect the competitive nature of a firm and do not appear to have improvements in the productivity. These improvements tend to be in areas which change the basic nature of the firm and the way the firm competes in the market. 11

This conclusion concurs with Strassman's conclusions for strategic improvements. He analyzed the benefits in a framework of three different categories; direct, indirect and inferred. Direct are those areas which are amenable to typical cost benefit analysis. Indirect and inferred are areas which affect the company but are elusive to analyze.

\subsubsection{Indirect benefits}

This area includes risk reduction, performance improvement, and cost avoidance These areas require the generation of comprehensive business plans and measures of performance. The business plans must be compared and rated against the measures of performance. Once the selected plan is approved, the performance of the implementation must be tracked. Quality, user satisfaction, error rates, delivery schedules and streamlining of the management structure are examples of the measures of performance which must be tracked.

The attainment of benefits are midrange in nature and further complicate the decision of the executive to implement. Returns may not be visible for several years. This will cause competition with the operational budget where immediate improvement in capability may decline.

$11_{F}$. Warren MCFarlan, "Information technology changes the way you compete", May-June 1984, Harvard Business Review. 


\subsubsection{Inferred benefits}

This area includes relationship design, competitive gains and competitive survival. Relationship designs are commonly referred to in the Department of Defense as interoperability issues. But this is a larger issue. Interoperability only allows one group to work with the

other. A complete relationship design for the Department of Defense would make the entire DOD seem as one seamless process. This could also be extended to the industrial sector which supports the DoD.

For the DOD the area of competitive gains and competitive survival tend to merge. This translates to performance of the Department to meet its operational requirements.

3. THE DOD CIM PROCESS

\subsection{ESTIMATE OF THE SITUATION IN THE GOVERNMENT}

The analysis of the possible benefits of information technology are not academic in nature. The DOD is being pressed to reduce the cost of doing business during the next several years. The DOD Corporate Information Management (CIM) effort plans on saving $\$ 2.1$ billion through the consolidation of the $\$ 9.2$ billion the DOD spends annually on the acquisition, operation and management of management information systems. At the same time the GAO has criticized the DOD CIM effort ${ }^{12}$ for the lack of quantifiable data to show how the program will save money. The DOD CIM program is required to show these benefits in the near term and for that reason the indirect and inferred benefits are not an immediate priority.

12"DEFENSE ADP, Corporate Information Management Savings Estimates Are Not Supported", United States General Accounting Office, February, 22, 1991 
While these are significant savings by themselves, the savings in information technology is not the primary effort of the DOD CIM program. It's primary focus is the improvement of business processes within the DoD. As stated to congress by Strassman 13 , "Information technology should be seen only as the rails on which the OMR freight train can roll to deliver its results.

\subsubsection{OVERLAPING REQUIREMENTS}

The Department of Defense is composed of the four armed services and many separate agencies. Each organization has interpreted the myriad of laws and interpreted these constraints into the most optimal business process envisioned by that organization. Each organization is different in many minor ways. Over a period of time the specific implementation becomes a requirement of its own. The focus on the laws and constraints is long since lost.

The initial plan for the DoD CIM program is to analyze each of the various business processes which are in the DoD. This will determine the areas where similar business processes exist which can be supported by information technology.

\subsubsection{NON-OVERLAPPING IMPLEMENTATIONS}

As $G A O$ noted in their report to congress ${ }^{14}$, there were 30 civilian personnel pay systems in the DoD. This would result in over 100 different

${ }^{13}$ To the House Armed Services Committee, Readiness Subcommittee, 23 April 1991.

${ }^{14}$ GAO Report to the Chairman, Subcommittee on Readiness, Committee on Armed Services, House of Representatives, "Defense ADP, Corporate Information Management Initiative Faces Significant Challenges," April 1991 
implementations for different hardware platforms. Each system needed separate development and needs continual maintenance. This maintenance requires a budget of over $\$ 7$ billion.

\subsection{FOCUS OF PROGRAM}

\subsubsection{FOCUS AREAS}

In order to show near time return on the project the DOD CIM has initially focused on the following eight areas:

Civilian Payroll

Contract Payment

Financial Operations

Material Management
Civilian Personnel

Distribution Centers

Government Furnished Material Medical

\subsubsection{FUTURE AREAS}

The initial area will not apply to the area of Command and Control or imbedded software. This area is highly specialized and would not be conducive to consolidation. There may be some areas, such as air tasking orders, which could be improved, however for the time being these areas are not being addressed.

The duplication which occurs in the DoD also occurs with all 23 federal agencies. I expect this duplication is a possible area for future work. This would encompass the entire executive portion of the federal government. (The judicial side is unique and too small to apply large scale business process to and the legislative side would exempt themselves from such an approach!) The approach of enlarging the DOD CIM effort to the entire government could indeed enlarge the amount of government savings.

\subsection{THE DEVELOPMENT PROCESS}

3.3.1. TOP DOWN APPROACH

The present situation in the federal government has resulted because of a lack of centralized planning. Each agency working to reduce its 
operational costs while responding to the external constraints of the agency. Under the DOD CIM concept there is a central authority which will provide the DOD vision and direction. This direction will not only keep the acquisition of information technology consolidated but it will keep the focus on consolidated business processes.

3.3.2. STRATEGIES FOR IMPLEMENTATION 15

One of the earliest and critical efforts of the DOD CIM is development of process models for all of the DoD's major functional areas noted above. This will ensure requirements are incorporated and drive future information system implementations. This is a form of knowledge engineering where each department's process will be analyzed.

The second strategy will be the identification of measures of effectiveness and efficiency for business processes. This will allow proper controls for investment in information technology which will result in quality, reduced costs, increased productivity. This will allow benchmarking against the best comparable achievement in and out of the government.

When researching this paper, I accessed an on-line data base. This resulted in a charge of $\$ 7.80$. This type of fee for service will be adopted for information system assets. The management of expenditures (third strategy) will be a management tool for assessing the system's efficiency.

Common information systems hold promise to reduce the costs of information system service. CASE tools will be used to the maximum extent

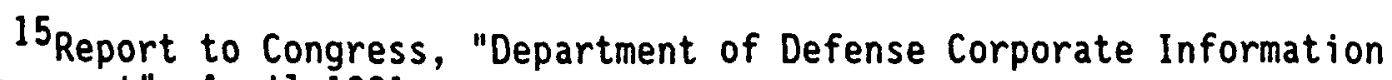
Management", Apri1 1991 
possible to ensure a cohesive design from the business process to the development of code. This technology will also allow us to reuse a certain amount of code that is in existence to reduce the amount of money spent on maintenance and future upgrades ${ }^{16}$.

The use of standards or open systems architectures will be promoted within the context of the DOD CIM. This will have the long term effect of allowing future systems to be purchased and integrated into the system. The existing Defense Data Network is an example of a system which, using government unique standards, is preventing adoption of commercial capability and equipment. In a similar manner it is required that data standards be developed to ensure that the information passed over the open systems be clearly understood.

Another strategy of the DoD CIM program is to improve the life-cycle management methodology of the entire process of information system acquisition and operation. This will enable easier analysis of the indirect and inferred benefit areas.

As a final part of the strategy the DoD CIM program is trying to educate people to the value of the program. This area needs to be improved. As I have discussed this program with various people it is only seen from the point of view of the information technologist. I believe this is caused by the method of funding used for the program. The 1991 Defense Appropriations Act reduced the DoD operation and maintenance budget for information technology development and modernization by $27 \%$, from $\$ 1.374$ billion to $\$ 1$ billion. The $\$ 1$ billion was moved to OSD as the

${ }^{16}$ Charles R Necco, "Current Usage of Case Software", Journal of Systems Management, May 1989 
foundation for the DOD CIM program. Of this money $\$ 700$ million was returned to the military departments to continue efforts which were judged by OSD to require continuation. This resulted in $\$ 300 \mathrm{million}$ for the basic program. If we really are committed to the effort one would believe that the money should be taken from where it is saved, i.e.. the eight initial focus areas. This would demonstrate the involvement of these functional areas and could improve the understanding of the DOD CIM program. Also there is no analysis which shows that this budget can accomplish the required integration with a reduction of the budget by $27 \%$.

\section{CIVILIAN SECTOR "CIM" EFFORTS}

In order to appraise the effectiveness of the DOD CIM effort to increase the productivity of the DoD it is appropriate to baseline the process to the approach to the civilian sector.

\section{1. "BUSINESS PROCESS REDESIGN"}

Davenport and Short 17 investigated the application of a very similar "CIM" technique to several corporations. They have described the process of "business redesign" as one consisting of a five steps process.

Develop Business Vision and Process Objectives: These include objectives such as cost reduction, time reduction, output quality and quality of worklife/learning/empowerment. For the moment the driving factor for the DOD has been identified as cost reduction, however it is clear that the other goals are areas that the Government can improve on. Identify Processes to Be Redesigned: The limitations of impact of the

17 Thomas H. Davenport and James E. short, "The New Industrial Engineering: Information Technology and Business Process Redesign", Summer 1990, Sloan Management Review. 
on-going operations and cost associated with a program of this nature requires that "high-impact" areas be identified. Within the DoD we have identified an initial list of eight functional areas with possible addition of more in the future. It is interesting to note Davenport and Short's comment that this process in infectious; one success produces at least two more attempts. As always a satisfied customer is the best advertisement.

Ownership of the process is required in order to ensure that there is a buy -in by the users of the process ${ }^{18}$. Once again we have identified, through the Executive Level Working Group, owners of the process. If these people are successful, the remainder of the middle management should be involved and accepting of the process.

Understand and Measure Existing Processes: As noted by Davenport and Short, this area is not well understood in industry. They found one manufacturing company who had never measured the time from the placement of the order to the delivery of the product. The Federal Government needs to improve in this area.

I was recently reading the Washington Post and a manual was referenced as being a particular good one for consumers to understand the performance markings on automobile tires. The article went on to say to order it and expect to wait in excess of 6 weeks-"understand this is the government." We have a long way to go to improve this stereotype.

Identify Information Technology Levers: In the past the use of information technology was not considered until the process was

$18 \mathrm{~J}$. F. Rockart, "The Line Takes Leadership-IS Management in a Wired Society," Sloan Management Review, Summer 1988, Pp. 57-64 
established. The typical application of IT was to automate the manual process. Davenport and Short emphasize that the optimal process is one which has considered IT in the development of the process. They identified the following capabilities which should be understood by those who work on a business redesign:

Transactional

Geographical

Automational

Analytical

Informational

Sequential

Knowledge

Tracking

management

Disintermediation provides structure to an unstructured process

makes process independent of location

replace or reduce human labor

make complex analytical tools part of the process

bring information into the process

allow tasks to run in parallel vice serial

allows knowledge to enter and leave process

(note that this can be human or IT based knowledge)

tracking progress of items in process

improve chain of communication

This is also the role of the technology specialist in the DoD CIM project. While not specifically enumerated by policy ${ }^{19}$, their process of baselining against industry will ensure that the most optimal use of technology is incorporated.

Design and Build a Prototype of the Process: Here the value of the recently deveioped CASE tools cannot be understated. With this tool the process can be well thought out with IT being the tool itself.

Nonetheless a prototype installation can be useful to prove out the system. This can help in the buy-in process of the users and customers.

\subsection{EFFECTIVENESS OF THE PROCESS}

While this process is new to the DoD it exists in the civilian sector

${ }^{19}$ Dr. Masterisch, CIM program policy, Feb 1992 
and the results which have been recorded are significant 20 .

Westinghouse reviewed its process with Portland General Electric and found that while an automation of the existing process with electronic data interchange (EDI) could save 10\%, reengineering the entire business process could save much more. "In one case, the time to execute a standard purchase order, for example, could be reduced from fifteen days to half a day; the cost could be reduced from almost $\$ 90$ to $\$ 10 . "$

US Sprint had difficulties in the billing of its customers. As a result of this they initiated a "systems improvement program." This program improved the composite internal quality index by more than $50 \%$ in one year.

\subsection{KNOWLEDGE MANAGEMENT AND THE BASELINE PROCESS}

What capabilities which will actually be included in the technology of the information system will depend on the task on hand and the awareness of the people involved in the business redesign process to the capabilities of information systems.

The baseline approach will ensure we adopt the best which has been deployed. For the DOD this may be sufficient, however the technology is rapidly changing. There are many opinions as to how fast this is moving but it is obvious that the components of information systems are changing at a breath taking rate.

The three components of information systems; computers, communications and software are each changing on a daily basis. The cost and performance

${ }^{20}$ Thomas H. Davenport and James E. Short, "The New Industrial Engineering: Information Technology and Business Process Redesign, Sloan Management Review, Summer 1990, pp. 18-20 
trend of computers has continued on a steep decline since the introduction of the first PC. Fiber optics are being installed and the cost for digital service continues to spiral down in the United States. Software may be the real "sleeper" in the group as we continually here of the increasing costs of software. In reality, the application programs such as the spreadsheet and project management tools make the "expensive" of 5 years ago available at low cost to any PC. Part of this is the ability of the software house to amortize the costs over thousands of customers.

Thus this baseline approach may get us the the performance we require, but there may be even further improvements available by pushing the technology a bit further than the systems which have been deployed and recognized as success. "Companies that ignore the information-technology revolution may find themselves left behind." 21 On the flip side there is a definite reduction in the risk with this approach.

5. ARTIFICIAL INTELLIGENCE AS A BASELINE

After examining the DOD CIM effort and the civilian business redesign process to question of the application of artificial intelligence to the program becomes one of "What has been implemented in an area which we can "baseline" against or is the technology known to the peopie responsible in the DOD CIM."

While there is no policy for the incc poration of artificial intelligence into the $\mathrm{DOD} \mathrm{CIM}^{22}$, the baselining/benchmarking process

21William E. Pracht, "Neural Networks for business Applications", Interface, summer 1991

22 Mr. John Redding, DoD Program Office, Feb 1992, 285-5310 
will incorporate AI into the program. Applications being investigated include an AI system to simplify the access to the types of DOD CIM software which is available. One in the medical is the interpretation of Electro Cardiograms in the health area.

\subsection{EXPERT SYSTEMS}

Expert systems require a thorough analys is of the knowledge base under consideration. This is essentially a library of the conditions or inference rules which can occur and the appropriate conclusion to be drawn from the conditions ${ }^{23}$. Systems can learn from the conditions and be "trained" from the occurrence of the conditions in a real world or the situations can be simulated and the simulated conditions loaded into the data base.

The strategic world of communications is normally transparent to the user. In order to provide this required transparency to the "communications system" is making millions of decisions every second. The decisions are based on prearranged network designs which have been modeled and incorporated into the system software. When it is all working, as designed, it is the epitome of efficiency. Enter a failure of a portion of the network and its capacity to pass traffic drops precipitously.

In order to keep the network efficiency as high as possible, skilled network controllers stand watch; three shifts each day, 365 days a year. Depending on the skill of the controller, traffic may be routed around problems in a transparent method or the user may be disappointed in the

${ }^{23}$ Frederick Hayes-Roth, "Knowledgebased Expert Systems: the State of the Art," Management Expert Systems, Addison-Wesley Publishing Company, 1988 
service. Take for example the 1990 failure of AT\&T in New York. Here the local power company requested and AT\&T agreed to a scheduled power outage. Operating on standby power the controller missed the point that after operating on batteries for an extended period, there would be insufficient capacity to start the generator-eventually resulting in a failure. This failure prevented users from obtaining service and AT\&T from collecting revenue. Other service providers, such as C\&P have automated this decision process. Under the same scenario, the equipment is capable of providing warning to the system controllers and in some cases correct the network configuration to avoid the outage.

USAA is at the forefront of using information technology to improve their service and reduce $\operatorname{costs}^{24}$. From the moment a customer makes a request, information technology comes into play. Even the mail which is sent to USAA is scanned in the mail room so it can be available to anyone of the customer service representatives. Part of their system includes an expert system to detect fraud. Installed as a prototype system, it was retained when it demonstrated an accuracy of over $90 \%$. McDermontt has a commitment to knowledge based systems - "expert systems - that will leverage the knowledge of our experts down to a level below them. People will be able to underwrite and approve loans, for example, at a level much higher than their education and experience would otherwise allow."

American Express uses an expert system to support their on-line capability to provide a card without any preset spending limit. When a

${ }^{24}$ Thomas Teal, "Service Comes First: An interview with USAA's Robert F. McDermontt, Harvard Business Review, September-October 1991 
purchase is called in for approval an expert system which integrates 13 different data bases to provide a recommendation to the person making the authorization decision 25 . This capability would not be possible without the assistance of an expert system to assure compliance with all of the business rules.

Digital Equipment uses an expert system to improve the configuration design process. ${ }^{26}$ This was necessary to ensure that the optimal system design was provided even with the large variety of equipment configurations. "It has proved extremely successful and is now being accessed, on a trial basis, by sales personnel in their order-generating process. Thus, customers in the field can be assured that their orders are appropriate and fully specified at the time they are entered.

\subsection{NEURAL NETWORKS}

A more recent technology is that provided by neural networks. In fact the neural network market is expected to expand from $\$ 7$ million in 1987 to $\$ 365$ million in 1993.

This area Neural networks learn in a similar manner as the human brain. The use of a neural network is appropriate when there are data and conclusions which can be drawn from the data--but the process is not known. The neural network can learn from the data and make predictions based on the data provided. These networks are essentially good at what humans are good at; distinguishing patterns or learning complex

${ }^{25}$ Leonard-Barton, Dorothy and John J. Sviokla, "Putting Expert Systems to Work," Harvard Business Review, March-April 1988, pp. 91-98

${ }^{26}$ Robert I. Benjamin, John R. Rockert, Michael S. Scott Morton, John Wyman, "Information Technology: A Strategic Opportunity", Sloan Management Review, Spring 1984 
relationships among elements of a data base.

While expert system rule based approaches have proved less than satisfactory for mortgage assessment, two companies have developed neural networks to assess mortgage risk. These systems are capable of addressing more soft type of information. These systems have shown that the systems can analyze the information and draw valid conclusions from large sets of data. The system is notable in that it learns from its own data and as such continues to adapt to the market.

Other areas where success has been obtained include forecasting the stock market. Neuralware, Inc. 27 developed a system which rated an accuracy of $61 \%$ of the time vice the previous best method (ten-week moving average) of $53 \%$ of the time. Pracht makes the point that while this type of technology is developing in industry, the competitive advantage of the newest technology prevents corporations from sharing with possible competitors.

\subsection{APPLICATION TO THE DOD CIM}

The literature is full of examples of the use artificial intelligence within information systems. These applications include many situations where the application provides a strategic edge to the company. With items such as these available as a baseline AI should find many areas where it will be incorporated as a direct result of the business redesign.

6. CONCLUSIONS

6.1. TOTAL QUALITY MANAGEMENT (TQM)

27 William E. Pracht, "Neural Networks for Business Applications," Interface, summer 1991 
The similarity of the DOD CIM program to the TQM initiative is startling. TQM focuses in on the process in a similar manner -- process review, measures of performance, and monitoring of the improvements. The TQM process has proven effective with many industries. The DOD CIM program enlarges this to add focus on the use of information technology. This focus should have a positive impact to the entire business process of the DoD.

\subsection{REASONS TO IMPLEMENT}

The above cases display strategic improvements in the ability of a company to compete in the marketplace. While these improvements are difficult to measure, the benefits are there. The free market economy is driving companies to use this approach to increase their competitive edge.

As the size of the organization increases the effectiveness of this approach improves. The DOD is a large monopoly and may well show more improvement than the DOD CIM program has estimated and more than GAO has questioned. The competition which drives industry is other companies. We do not have this impetus, but we are driven by the reduced budget, our real competitor, to increase our capability at a lower cost.

"It is time to stop paving the cow paths. Instead of embedding outdated processes in silicon and software, we should obliterate them and start over. We should "reongineer" our businesses: use the power of modern information technology to radically redesign our business processes in order to achieve dramatic improvements in their performance." 28

\subsection{ORGANIZATIONAL MOMENTUM}

28 Michael Hammer, "Harvard Business Review", July-August 1990 
In some areas this process is being accepted and in other there is a feeling that the process will tear down the existing accomplishments and take information technology development away from the user and result in the user requirements not being satisfied. The business review process should, for the functional areas identified, improve this process.

There are other concerns with the business redesign process that the middle level managers will resist the process because it is indeed them which could be replaced by the technology 29 . This may be the hardest area to overcome. With the reduction in the budget scheduled and anticipated reduction in the manpower levels in the DOD this could indeed be a concern. USAA recognized and prevented this by guaranteeing that no employees would be lost due to the increased use of technology. This may well be the hardest area to overcome and may require a National Strategy to address.

Typical personnel in the DOD are not known for risk taking and innovation. With a KAI score of over 140, I find the challenge refreshing even at the risk of major restructuring in the operation of the DoD. If we do not take this risk we are doomed to remain inefficient.

\subsubsection{ARTIFICIAL INTELLIGENCE}

The application of information technology should be restricted to only that which adds value to the business process. The DOD CIM process should identify through benchmarking and analysis of the business process that which will add value. Artificial Intelligence (AI) is providing value to many processes in the commercial world. As Tom Peters stated "... any

${ }^{29}$ Stewart L. Stokes, Jr., "IS Without Managers," Information Strategy, Fall 1991 
senior manager in any business of almost any size who isn't at least

learning about $A I$, and sticking a tenative toe or two into AI's waters, is simply out of step, dangerously so." 30

${ }^{30}$ Tom Peters, forward to "The Rise of the Expert Company" by, Feigenbaum, McCorduck, and $\mathrm{Ni}, \mathrm{p}$. xiii. 